\title{
Once-daily metoprolol for hypertension
}

\author{
M. J. WARD \\ M.R.C.P.
}

\author{
J. M. ROLAND \\ B.Sc., M.R.C.P.
}

\author{
D. C. BANKS \\ M.D., F.R.C.P. \\ Dept of Therapeutics, City Hospital, Hucknall Road, Nottingham
}

\begin{abstract}
Summary
In a randomized cross-over trial the antihypertensive effect of metoprolol given once daily was compared with its effects after twice-daily dosage. Metoprolol given as a single morning dose had a useful antihypertensive effect for $24 \mathrm{hr}$ and may be given in this way for the treatment of hypertension.
\end{abstract}

\section{Introduction}

One of the problems encountered in the treatment of hypertension is that the long duration of therapy coupled with multiple dosage regimens in asymptomatic patients lead to poor compliance (Sackett and Haynes, 1976). Once-daily treatment regimens with $\beta$-adrenoceptor blockers other than metoprolol have been shown to be effective (Wilcox, 1978; Watson, Stallard and Littler, 1980). It was decided to see if the same is true for the cardioselective $\beta$-blocker, metoprolol.

\section{Patients and methods}

Twenty-three patients were studied, all had newly-diagnosed moderate essential hypertension with a standing diastolic $\mathrm{BP}$ (phase $\mathrm{V}$ ) $>100 \mathrm{mmHg}$, on 3 separate occasions before treatment. The study was composed of 2 treatment periods: in the first, the patients were treated in an open manner with increasing doses of metoprolol given twice daily until their diastolic pressure was $<95 \mathrm{mmHg}$. They then entered the second period of the study which was double-blind and consisted of 3 randomly allocated 4-week periods. In each of these 4-week periods they were given the same dose of metoprolol which controlled their BP in the open treatment period either as a once-daily dose in the morning with evening placebo tablets, or in the evening with morning placebo tablets, or as a twice-daily dose given in the morning and evening. Patients were seen fortnightly, they were asked to take their tablets on rising and $12 \mathrm{hr}$ later but to omit the morning dose on each alternate visit to the clinic. Recordings of BP were measured with a London
School of Hygiene and Tropical Medicine sphygmomanometer to overcome observer bias. The diastolic BP was taken as the point of disappearance of Korotkoff's sounds. Compliance in taking tablets was assessed by a tablet count.

\section{Results}

Of the 23 patients, 8 were excluded, 7 required the addition of a diuretic to control their BP, and one developed left ventricular failure.

Initial BPs, lying and standing and the effect of the 3 treatment phases in the remaining 15 patients are shown in Fig. 1. Standing and lying BPs were reduced by both once- and twice-daily treatments. The fall in mean BP was by $20 \%$ (standing) and $17 \%$ (lying) when readings were taken $12 \mathrm{hr}$ after the last dose with twice-daily treatment, and by $22 \%$ (standing) and $18 \%$ (lying) when they were taken at the same time $12 \mathrm{hr}$ after treatment taken in the evening only, and by $14 \%$ standing and lying $24 \mathrm{hr}$ after treatment given as a single dose in the morning. The reduction in the standing and lying $\mathrm{BP}$, both systolic and diastolic was significant $(P<0.005$, paired $t$ test) and clinically useful $24 \mathrm{hr}$ after the last dose. When the active treatments were compared with each other, the standing systolic BP $24 \mathrm{hr}$ after the last dose with once-daily treatment was just significantly higher than that $12 \mathrm{hr}$ after treatment with the twice-daily regimen $(P=0.05$, paired $t$ test), but the antihypertensive effect was still clinically useful. There was no difference between once- and twice-daily dosage with any of the other values.

The mean dose of metoprolol used was $150 \mathrm{mg}$ (range $100-300 \mathrm{mg}$ ).

\section{Discussion}

Most $\beta$-adrenoceptor blockers have a short half-life of $<9 \mathrm{hr}$ (Johnsson and Regardh, 1976) but their pharmacological half-life, e.g. their $\beta$ adrenoceptor blocking effect is longer lasting. In 


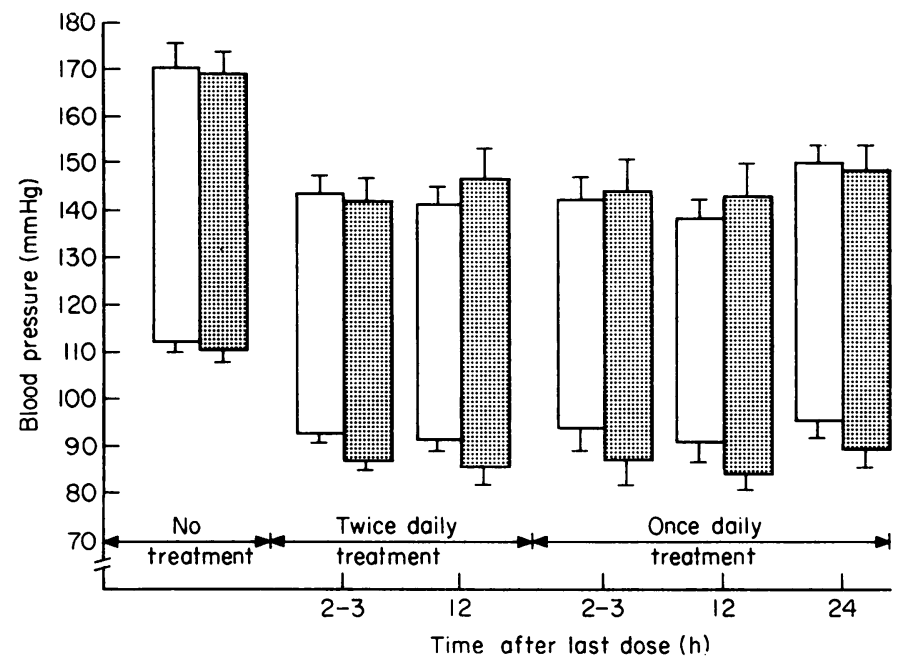

FIG. 1. Mean blood pressure ( $\mathrm{mmHg} \pm$ s.e. mean) systolic and diastolic, standing ( $\square$ ), lying (ख्:), with no treatment, twice anÆ once daily treatment, $2-3 \mathrm{hr}, 12 \mathrm{hr}, 24 \mathrm{hr}$ after the last dose.

this study the reduction in BP $24 \mathrm{hr}$ after single daily dosage was clinically useful.

Slow-release preparations of $\beta$-blockers are now available but are probably not required for the treatment of hypertension. It is likely that metoprolol and atenolol have an equipotent antihypertensive effect (Comerford and Besterman, 1980) and both may be used on a once-daily basis for hypertension. However, the treatment of angina requiring control of the exercising heart rate may need more frequent dosage.

To improve patient compliance in taking tablets for hypertension the regimen used must be simple. Errors in tablet taking increase with both an increase in the number of drugs and the number of daily doses prescribed (Porter, 1969; General Practitioner Research Group, 1970). Giving metoprolol once daily may improve compliance in hypertensive patients.

\section{References}

COMERFORD, M.B. \& Besterman, E. (1980) Dosing interva疋 in beta-blocker therapy. Lancet, ii, 1196.

General Practitioner Research Group (1970) Dojage schedules in General Practice. Practitioner, 204, 719, 그․

Johnsson, G. \& Regardh, C.G. (1976) Clinical pharma cokinetics of $\beta$-adrenoceptor blocking drugs. Clinic Pharmacokinetics, 1, 233.

PorTer, A.M.W. (1969) Drug defaulting in a Gener黑 Practice. British Medical Journal, 1, 218.

SACKetT, D.L. \& HAYNeS, R.B. (1976) Compliance wi Therapeutic Regimens. Johns Hopkins University Press, Baltimore and London.

Watson, R.D.S., Stallard, T.J. \& Littler, W.A. (1980) Comparison of once- and twice-daily administration of acebutalol in hypertension. British Journal of Clinic Pharmacology, 9, 209.

Wilcox, R.G. (1978) Randomised study of six beta blockers and a thiazide in essential hypertension. British Medical Journal, 2, 383. 